\title{
Non-dysraphic Subpial Intramedullary Lipoma of Cervicothoracic Spine
}

\author{
Aliza Hamal $M B B S^{1}$, Anjan Singh Karki $M S^{2}$ iD, Ashim Gurung $M S^{3}$ iD, Dipendra Kumar \\ Shrestha $M \boldsymbol{C h}^{4}$ iD, Sushil Krishna Shilpakar $M S^{5}$ iD \\ ${ }^{1}$ Department of General Surgery, Tribhuvan University Teaching Hospital, Kathmandu, Nepal \\ 2,3,4,5 Department of Neurosurgery, Tribhuvan University Teaching Hospital, Kathmandu, Nepal
}

Date of submission: $4^{\text {th }}$ April 2021

Date of acceptance: $25^{\text {th }}$ September 2021

Date of publication: $1^{\text {st }}$ December 2021

\begin{abstract}
Intramedullary spinal cord tumors are rare and comprise less than one percentage of all central nervous system (CNS) neoplasms. When encountered, most are found in the lumbosacral region with coinciding spinal dysraphism. Here, we discuss a case of isolated non-dysraphic intramedullary lipoma of cervicothoracic spine in an adolescent who was surgically managed with posterior decompression and subtotal resection via laminoplasty.

A 21-year-old male adolescent, without a history of spinal dysraphism, presented with a progressive sensory ataxia. This manifestation was attributed to magnetic resonance documented intramedullary lipoma, extending from $\mathrm{C} 7$ to T2 spinal level. Patient underwent subtotal surgical resection of the lesion; and histopathology report was confirmed as spinal lipoma.

Surgical management of this rare pathology has a wide variety of options depending on clinical presentation. In our case, a subtotal resection and laminoplasty was achieved with no further worsening of neurologic symptoms.
\end{abstract}

Key words: Intramedullary spinal lipoma, Laminoplasty, Non-dysraphic.

\section{Introduction}

Tntra tramedullary spinal lipomas, excluding those associated with dysraphism, comprise about one percentage of all spinal cord tumors. ${ }^{1}$ Several reports in the literature have discussed spinal cord lipomas, especially in the pediatric population; however, there are fewer reports of isolated cervical cord lipomas. Intradural spinal lipomas typically present around the second and third decades of life. Both genders are equally affected. Being non-dysraphic lesions, they are not associated with vertebral and dermal

Access this article online
Website: https://www.nepjol.info/index.php/NJN
DOI: https://doi.org/10.3126/njn.v18i4.35418
HOW TO CITE
Hamal A, Karki AS, Gurung A, Shrestha DK, Shilpakar SK. Non-
dysraphic Subpial Intramedullary Lipoma of Cervicothoracic
Spine. NJNS. 2021;18(4):68-71.

Address for correspondence:

Dr. Aliza Hamal

Tribhuvan University Teaching Hospital,

Maharajgunj Medical Campus,

Institute of Medicine,

Maharajgunj, Kathmandu, Nepal.

E-mail: alizahamal123@gmail.com

Phone: +977 9843565855

Copyright (C) 2021 Nepalese Society of Neurosurgeons (NESON)

ISSN: 1813-1948 (Print), 1813-1956 (Online)

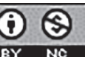

This work is licensed under a Creative Commons Attribution-Non Commercial 4.0 International License. anomalies. Herein, we report a young male with a large intramedullary subpial lipoma of cervicothoracic junction without spinal dysraphism, who underwent subtotal resection with laminoplasty.

\section{Case report}

A 21-year-old male adolescent presented in Neurosurgical Outpatient Department with one-year history of progressive sensory ataxia with swaying towards right side. He had discoordination of his legs and had difficult in walking. In addition to this, he complained of lower back pain with feeling of tingling and numbness radiating to bilateral lower limbs reaching up to the ankles with McCormick scale of 2. His neurological examination revealed decreased power of right EHL (4/5), impaired joint and position sense with positive Romberg's sign. The patient had a good range of motion in his neck. The strength in all the major group of muscles were intact with good muscle tone and bulk, normal reflexes and there were no myelopathic signs.

Magnetic resonance imaging (MRI) revealed an intradural, intramedullary lesion, measuring $6.2 \times 1.5$ $\mathrm{x} 2 \mathrm{~cm}^{3}$, extending from $\mathrm{C} 7$ to $\mathrm{T} 2$ level, causing severe cord compression in the posterior aspect of the spinal canal. There were no features of any dysraphic vertebral anomalies. (Figure 1) The lesion appeared hyperintense on T1- and hypointense on T2- weighted images. These aforementioned radiological findings were consistent with a spinal lipoma. 


\section{Non-dysraphic Subpial Intramedullary Lipoma of Cervicothoracic Spine}

The patient was planned for surgical resection of the spinal lipoma via three-level laminectomies, followed by laminoplasty using trough plates under Neuroelectrophysiological monitoring. High-dose steroid (intravenous Dexamethasone $4 \mathrm{mg}$ QID) was started 24 hours prior to surgical intervention.

Patient was placed in a prone position on a sponge box and horseshoe Mayfield headrest with Gardener-Well tongs, attached to $3-\mathrm{Kg}$ weight and was given endotracheal general anesthesia. Muscle relaxants and deep sedation was avoided as the patient was prepared for continuous neuro-monitoring. A large vertical posterior midline incision was made, starting from the spinous processes of C6 to T3 level. The paraspinous muscles were separated off the laminas via subperiosteal dissection to minimize bleeding. After confirming the spinal level by fluoroscopy, three-level zip laminectomies of C7 to T2 were achieved, using NSK Neuro-electric drill. A midline durotomy was achieved, using number-11 blade scalpel

On macroscopic inspection, the tumor was sausagelike, well-circumscribed, yellowish fleshy extending subpially and significantly compressing the cord. (Figure 2A) Operating microscope was used for better visualization, magnification and illumination.The lesion had embedded into the cord; and there was an exophytic component as well. There was significant arachnoid adhesion and dural thickening. Multiple nerve roots were seen intertwined between the fatty tissues particularly on the left side. The fatty tissue was meticulously removed in piecemeal manner, using ultrasonic aspiration; and hemostasis was maintained using low-voltage bipolar coagulation with copious and continuous irrigation to avoid thermal injury to the cord. As the tumor was embedded within the cord and there was no obvious tumor-cord interphase, a thin strip of fatty tissue was deliberately left behind to avoid damage to normal neural tissue; and in addition, excessive cauterization was avoided. The lesion was subtotally (80 percentage) resected and throughout the resection process, the neuro-electrophysiological monitoring data remained unchanged. After thorough irrigation and hemostasis, the dura was closed continuously in water-tight fashion. (Figure 2B). Laminoplasty was done by fixing the long $\mathrm{C} 7$ to $\mathrm{T} 2$ bone segment with titanium trough plates and screws.

Postoperative course was uneventful. Patient was put a cervicothoracic brace; and early ambulation and physiotherapy were started from postoperative day two (POD \#2). Postoperatively, there was gradually improvement in his neurological symptoms. He was able to walk with minimal assistance and there was gradual improvement in sensory function of his lower limbs. Patient was discharged on POD\#8; and staples were removed on POD\#14 in the Neurosurgical clinic.

Histopathological report revealed predominantly mature adipocytes intertwined with thickened bands of connective tissue within the adipose tissue. The pathological description was consistent with lipoma. (Figure 3) One-month follow up MRI revealed a thin layer of residual tumor embedded in the cord with no evidence of compression. (Figure 4)
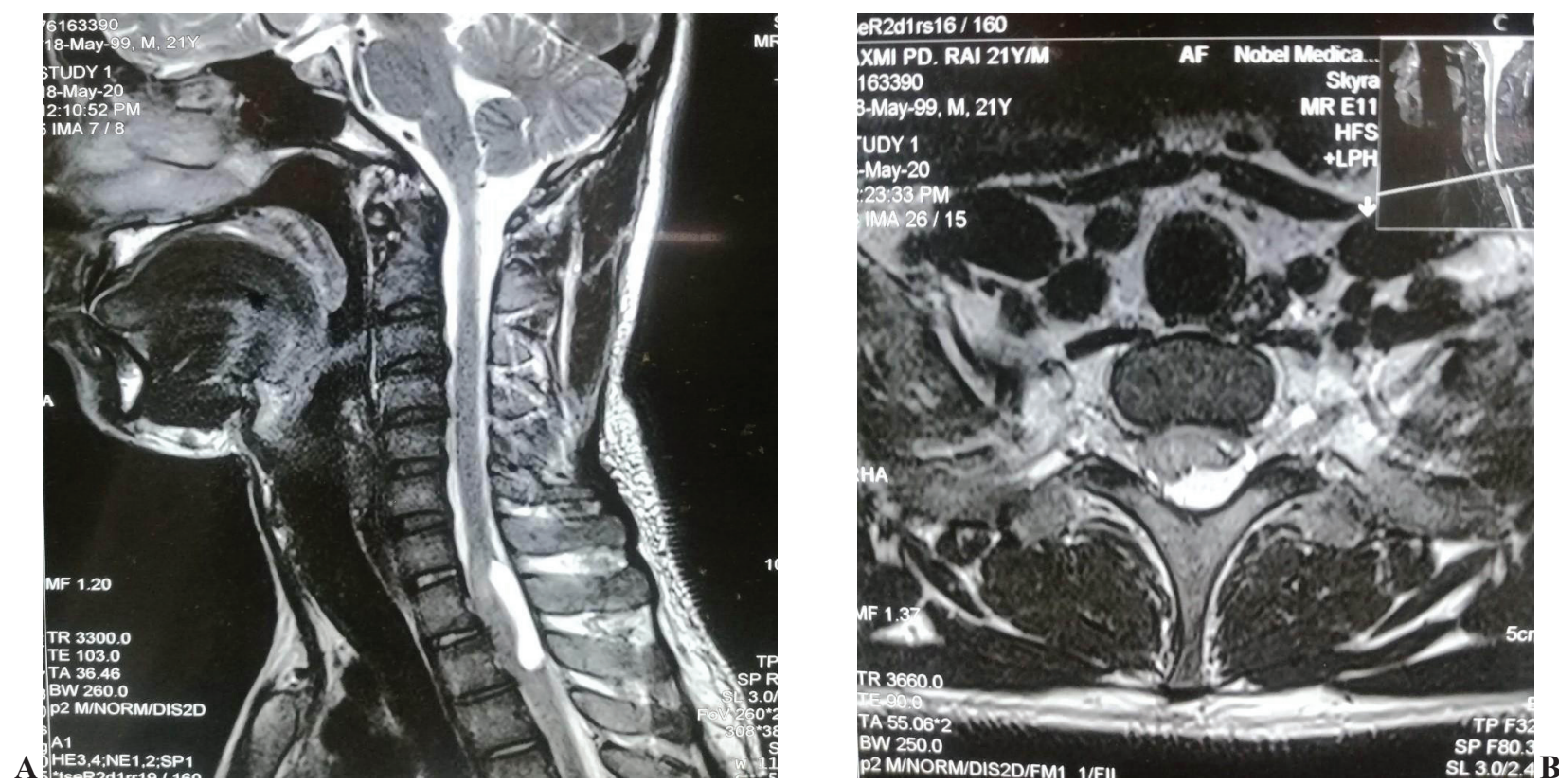

Figure 1: (A) Preoperative MRI, T1 sagittal section showing a hyperintense intradural, intramedullary lesion, measuring $6.2 \times 1.3 \times 2 \mathrm{~cm} 3$, extending from C7 to T2 level, causing severe cord compression in the posterior aspect of the spinal canal. (B) Preoperative MRI, T1 transverse section showing a hyperintense intradural, intramedullary lesion, causing severe cord compression in the posterior aspect of the spinal canal. 


\section{Hamal et al}
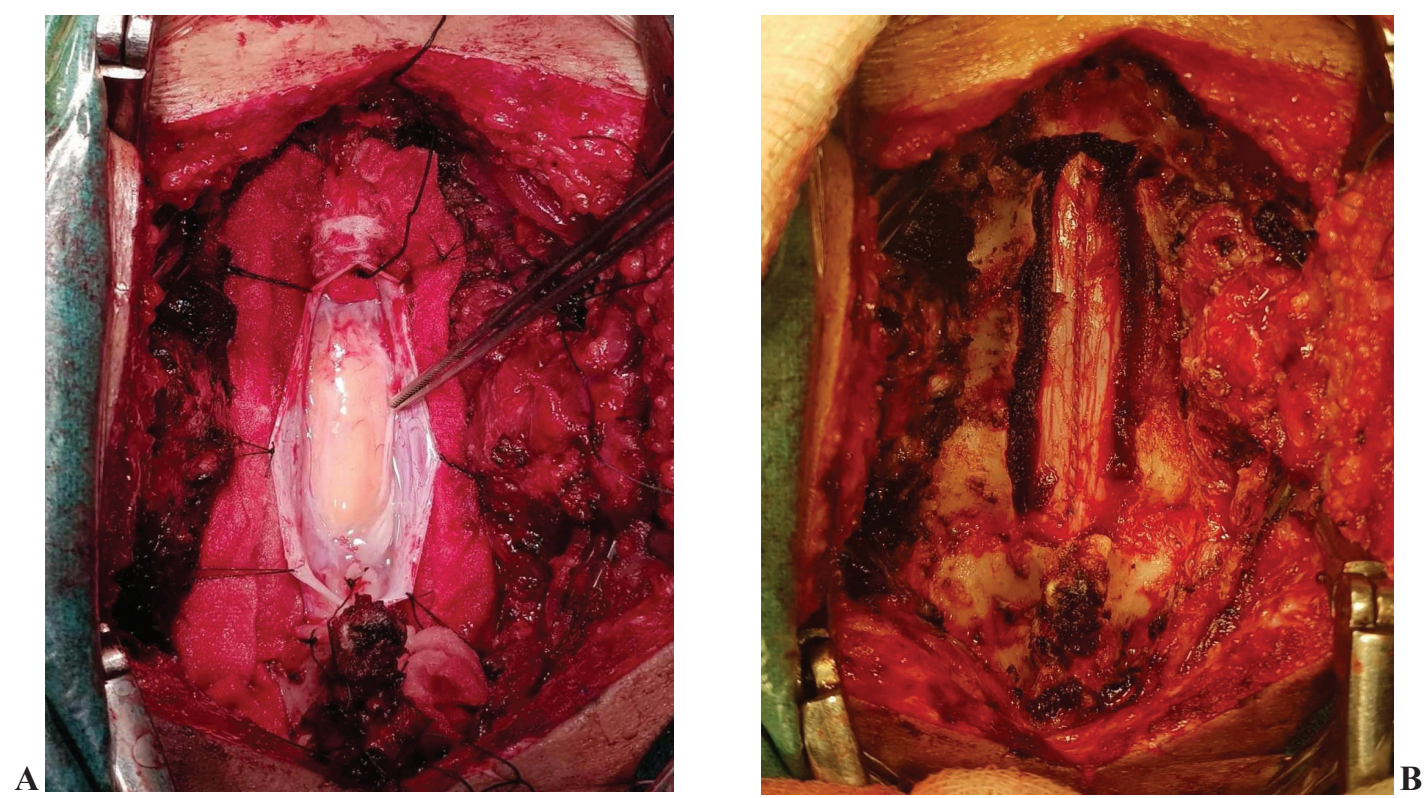

Figure 2: (A) Intraoperative picture demonstrating a sausage-like, well-circumscribed, yellowish fatty tumor extending subpially and significantly compressing the cord. (B) Intraoperative pictures demonstrating dural closure in water-tight fashion.

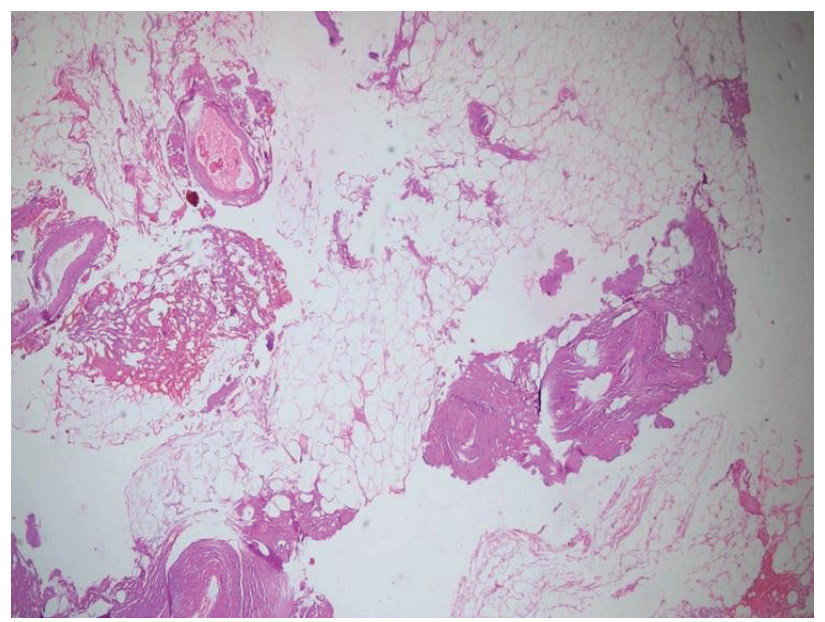

Figure 3: Histopathological slides showing predominantly mature adipocytes intertwined with thickened bands of connective tissue within the adipose tissue consistent with lipoma.

\section{Discussion}

Typically, most spinal lipomas are associated with spinal dysraphism and are predominantly located in the lumbosacral spine. ${ }^{2}$ True subpial intramedullary spinal cord lipomas are rare, often have poor prognosis ${ }^{3}$ and accounts for less than one percentage of all spinal cord lesions. ${ }^{4}$

Histologically, these tumors consist of ordinary mature adipose tissue intertwined with connective tissues, and are believed to originate from nests of ectopic tissue. ${ }^{5}$ There are several theories in regards to the developmental mechanism of spinal cord lipomas.

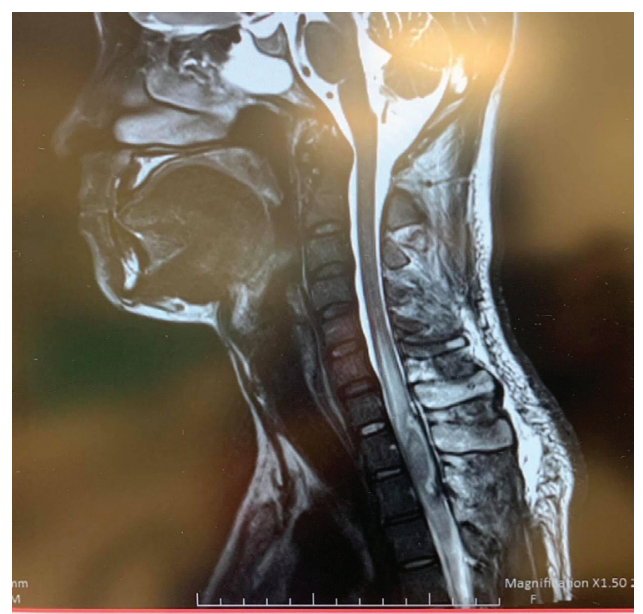

Figure 4: One-month follow up MRI revealing a thin layer of residual tumor embedded in the cord and minimal cord edema proximally with no evidence of compression.

Most theories contribute the development of dysraphic spinal cord lipomas to an adipocyte migration issue during embryological development. ${ }^{6}$ Unfortunately, the pathogenesis of non-dysraphic spinal cord lipomas is poorly understood.

Intradural lipomas are a subset of spinal lipomas. They are typically intradural, subpial, juxtamedullary lesions ${ }^{7}$ and rarely intramedullary lesions. ${ }^{8}$ Our patient had intradural, intramedullary subpial lipoma with an exophytic component.

Spinal lipomas tend to have long indolent clinical courses, followed by a rapid decline in neurological function. $^{3}$ In various reported case series, patients 


\section{Non-dysraphic Subpial Intramedullary Lipoma of Cervicothoracic Spine}

presented with variable degrees of neck or back pain, gait difficulties, weakness and dysesthetic symptoms. ${ }^{1,3}$ The typical clinical manifestation of cervical intramedullary lipomas included ataxia, cervical axis pain, dysesthesias, and progressive quadriparesis. Frequently, adults exhibited more subtle features, characterized by slowly-progressive myelopathy. When compression became significant, the patients finally developed myelopathy. ${ }^{1,3}$ However, in our case, the patient presented with sensory ataxia, discoordination and difficulty in walking at night time for over a year but without obvious myelopathic features.

Early diagnosis and appropriate treatment strategy are of utmost importance to prevent prolonged cord compression, resulting in irreversible neurological damage. $^{3}$ Magnetic Resonance Imaging (MRI) is considered as the investigation of choice for this tumor; and typically, it demonstrates $\mathrm{T} 1$ hyperintense and $\mathrm{T} 2$ hypointense well-circumscribed non-enhancing mass with suppression on fat saturation sequence. Generally, the cord is significantly compressed, distorted or displaced.

Surgical management of spinal cord lipomas is controversial. Spectrum of treatment options is available, which include observation, $\mathrm{CO} 2$ laser ablation, cord decompression via laminectomy and duroplasty, biopsy, subtotal resection, and gross total resection. Varying clinical scenarios may warrant different treatment options. If severe progressive neurological deficits are observed, decompression and safe resection should be the recommended treatment. If the lesion is asymptomatic and incidentally diagnosed, then mere observation may suffice initially. Functional improvement is anticipated after cord decompression due to their indolent behavior; however, the adherent nature may cause an intrinsic component of neurologic dysfunction. ${ }^{9}$ To prevent additional neurological deficits, the cardinal aim of optimal treatment strategy should be adequate decompression (partial/subtotal resection) rather than radical resection (gross total excision) because generally, there is no clear interphase between the tumor and the normal spinal cord. ${ }^{1,3,10}$ For the very reason, we performed subtotal resection, leaving behind a strip of imbedded tumor tissue. Apart from avoidance of excessive use of bipolar cauterization to prevent thermal injury to the adjacent normal neural tissue, it is essential to routinely use motor evoked potentials for resection of these lesions. ${ }^{3,10}$ Use of intraoperative ultrasonography, ultrasonic aspirator, $\mathrm{CO} 2$ laser, and both motor evoked and somatosensory evoked potentials can be helpful during the resection of spinal cord lipomas. In our case, we used ultrasonic aspirator and neuro-monitor

\section{Conclusion}

We report a rare case of a cervicothoracic cord lipoma in an adolescent where diagnosis was made by
MR imaging and confirmed by histopathology. Surgical management of this rare pathology has a wide variety of options depending on clinical presentation. In our case, subtotal resection was successfully achieved with no further worsening of neurologic symptoms

Conflict of Interest: None

Source(s) of support: None

\section{References}

1. Bhatoe HS, Singh P, Chaturvedi A, Sahai K, Dutta V, Sahoo PK. Nondysraphic intramedullary spinal cord lipomas: a review. Neurosurg Focus. 2005;18(2):ECP1.https://doi.org/10.3171/ foc. 2005.18 .2 .10

2. Rogers HM, Long DM, Chou SN, French LA. Lipomas of the spinal cord and cauda equina. J Neurosurg. 1971;34:349-54. https://doi.org/10.3171/ jns.1971.34.3.0349

3. Lee M, Rezai AR, Abbott R, Coelho DH, Epstein FJ. Intramedullary spinal cord lipomas. J Neurosurg. 1995;82(3):394-400.https://doi.org/10.3171/ jns.1995.82.3.0394

4. Caram PC, Carton CA, Scarcella G. Intradural lipomas of the spinal cord; with particular emphasis on the intramedullary lipomas. J Neurosurg. 1957;14:28-42. https://doi.org/10.3171/jns.1957.14.1.0028

5. Mrabet A, Zouari R, Mouelhi T, Khouaja F, Ghariani MT, Hila A, Haddad A. Les lipomes intramédullaires cervicobulbaires. A propos d'un cas avec revue de la littérature [Cervicobulbar intramedullary lipoma. Apropos of a case with review of the literature]. Neurochirurgie. 1992;38(5):309-14. French. PMID: 1299777

6. Kim CH, Wang KC, Kim SK, et al. Spinal intramedullary lipoma: report of three cases. Spinal Cord 2003;41(5):310-315. https://doi.org/10.1038/ sj.sc. 3101441

7. Osborn AG. Diagnostic neuroradiology. Mosby Inc. (1994) ISBN:0801674867

8. Finn MA, Walker ML. Spinal lipomas: clinical spectrum, embryology, and treatment. Neurosurg Focus. 2007;23 (2): E10. https://doi.org/10.3171/ FOC-07/08/E10

9. Le Feuvre DEJ, Semple PL, Peter JC. Intradural cervical lipomas with intracranial extension: a management strategy based on a case report and review of the literature. Br J Neurosurg 2004;18(4): 385 388. https://doi.org/10.1080/02688690400005180

10. Chagla AS, Balasubramaniam S, Goel AH. A massive cervicomedullary intramedullary spinal cord lipoma. J Clin Neurosci. 2008;15:817-20. https://doi. org/10.1016/j.jocn.2006.07.018 